\title{
Efek Penggunaan Gadget terhadap Social Behavior Mahasiswa dalam Dimensi Globalisasi
}

\author{
Pandu Hyangsewu, Mohammad Rindu Fajar Islamy*, Muhamad Parhan, Risris Hari \\ Nugraha \\ Departemen Pendidikan Umum, Universitas Pendidikan Indonesia \\ Jl. Setiabudi No. 229, Isola, Sukasari, Bandung, Jawa Barat, Indonesia, 40154 \\ *Corresponding Author. e-mail: fajarislam2000@upi.edu
}

\begin{abstract}
Abstrak
Kehadiran gadget ditengah-tengah masyarakat kontemporer dalam arus globalisasi berpotensi memberikan dua sisi yang berbeda, positif maupun negatif. Tantangan utama sistem pendidikan di Indonesia saat ini adalah bagaimana para praktisi pendidikan proses pembelajaran yang dapat menjaga moralitas dan religiusitas dalam diri generasi muda dari pengaruh buruk globalisasi tersebut. Penelitian ini bertujuan dalam rangka mengeksplorasi dampak penggunaan gadget terhadap sikap social behaviour mahasiswa di perguruan tinggi. Metode penelitian menggunakan pendekatan mix method dengan menggabungkan kualitatif melalui teknik wawancara dengan kuantitatif dengan teknik questioner. Pengumpulan data menggunakan teknik random sampling. Adapun partisipan pada riset ini sejumlah 75 orang. Lalu data yang ditemukan di lapangan dianalisis dan divalidasi oleh ahli. Hasil penelitian menunjukkan adanya relevansi koneksitas antara penggunaan gadget dengan perubahan dinamika perilaku sosial pada mahasiswa di perguruan tinggi. 43,80\% mereka menghabiskan waktu lebih 10 jam perhari menggunakan gadget, Whatsapp menempati rangking pertama dalam pilihan platform, 45,90\% lebih menyukai gadget dari pada aktivitas sosial, $83,80 \%$ memiliki ketergantungan terhadap gadget. Globalisasi menjadi salah satu faktor penyebab perubahan arus aktivitas dan pola pemikiran pada masyarakat modern khususnya generasi milennial.
\end{abstract}

Kata Kunci: gadget, perilaku sosial mahasiswa, perguruan tinggi, globalisasi

\section{The Effects of Using Gadgets on Student Social Behaviour in Globalization Dimentions}

\begin{abstract}
The presence of gadgets during contemporary society in the flow of globalization provides two different sides, positive and negative. The main challenge of the education system in Indonesia today is how to start a learning process education that can maintain morality and religiosity in creating the bad effects of globalization. This study aims to explore the impact of using gadgets on the social behaviour attitudes of college students. The research method used a mixed approach method by combining qualitative through interview techniques with quantitative questionnaire techniques. Collecting data using random sampling techniques as participants in this research several 75 people. Then the data found in the field are analysed and validated by experts. The results showed the relevance of the connectivity between the use of gadgets and changes in the dynamics of social behaviour in college students. $43.80 \%$ of them spend more than 10 hours using gadgets, WhatsApp has been ranked first in the choice of platform, $45.90 \%$ prefers gadgets to social activities, $83.80 \%$ have a dependency on gadgets. Globalization is one of the factors causing changes in the flow of activities and thought patterns in modern society, especially the millennial generation.
\end{abstract}

Keywords: gadgets, social behaviour, students, college, globalization

How to Cite: Hyangsewu, P., Islamy, M., R. F., Parhan, M., \& Nugraha, R. H. (2021). Efek penggunaan gadget terhadap social behaviour mahasiswa dalam dimensi globalisasi. Jurnal Penelitian Ilmu Pendidikan, 14(2), 127136. doi: https://doi.org/10.21831/jpipfip.v14i1.39156.

Received 03-03-2021; Received in revised from 11-05-2021; Accepted 08-06-2021 
Jurnal Penelitian Ilmu Pendidikan, 14 (2), 2021 - 128

Hyangsewu, Islamy, Parhan, \& Nugraha

This is an open-access article under the CC-BY-SA license.

\section{PENDAHULUAN}

Akhir-akhir ini, dampak globalisasi semakin begitu dirasakan oleh dunia internasional. Dampaknya telah menyebar kepada seluruh aspek dan sendi-sendi kehidupan manusia baik secara makro maupun mikro. Globalisasi memberikan dampak kepada konsep sosiologis, sehingga melahirkan penataan bentuk dan jenis baru kelompok masyarakat dalam hubungan sosial (Albrow, Eade, Washbourne, \& Durrschmidt, 1994). Elbrow bahkan lebih lanjut menyoroti persoalan potensi kemungkinan yang lebih buruk akibat dampak ini yaitu adanya transformasi pola hubungan sosiologi bentuk negara yang lama kepada kerangka sosiologi baru yang bisa jadi akan berpotensi mewujudkan deteritorialisasi konsep komunitas yang tidak bisa dibayangkan. Pada aspek budaya, dalam sebuah studi riset yang dilakukan oleh Al-Rawashdeh, globalisasi turut serta berkontribusi besar merubah budaya politik di beberapa negara seperti Arab Saudi. Selain itu, ada pula beberapa aspek yang mengalami perubahan diakibatkan dampak dari globalisasi yaitu adanya pergeseran kehidupan budaya dan sosial, termasuk ketentuan pola perilaku, mazhab pemikiran, sikap psikologis, dan yang membentuk jati diri bangsa (Al-Rawashdeh, 2014). Temuan Al-Rawashdeh selaras dengan apa yang ditemukan oleh Wai Chung Ho dalam risetnya di mana globalisasi turut serta merubah kurikulum antara nilai-nilai budaya dan sosial kontemporer dan ideologi tradisional China dan Komunis antara kolektivisme dan individualism dan antara budaya nasional dan global (Law \& Ho, 2009).

Demikian pula dalam sektor ekonomi, studi yang dilakukan oleh Mah memperlihatkan adanya kecenderungan penurunan akibat globalisasi terhadap ketimpangan pendapatan ekonomi di negara Korea (Mah, 2002). Sektor pendidikan mengalami turbulensi yang lebih dahsyat, menurut beberapa ahli globalisasi cenderung mengubah sistem pendidikan tinggi dari layanan publik menjadi komoditas komersial yang dijual untuk mendapatkan keuntungan dengan hasil akhir yang tidak akan dilakukan oleh siswa dari kelas sosial bawah. Riset yang dieksplorasi oleh Machingambi membuktikan bahwa globalisasi cenderung mengabaikan budaya yang kaya dari masyarakat berkembang dan karenanya para pemimpin universitas dan pemerintah diperingatkan untuk tidak merangkul globalisasi secara tidak kritis (Machingambi, 2014). Para akademisi, intelektual, praktisi pendidikan internasional saat ini mencoba upaya-upaya serius dalam riset penelitiannya dalam rangka mengarahkan globalisasi agar lebih bermanfaat dan bernilai positif bagi masyarakat global utamanya dalam sektor pendidikan (Al-Thivierge, 2003; Bruner \& Iannarelli, 2011; Law \& Ho, 2009; London, 2010; Nieto, 2013; Tight, 2021; Utsumi, 2006; Weldon et al., 2011). Pakar pendidikan Lin Goodwin menganjurkan kepada para guru untuk beradaptasi dengan globalisasi dengan cara menumbuhkan empat dimensi dalam konteks globalisasi: kurikuler, profesional, moral, dan pribadi (Goodwin, 2020).

Kemunculan gadget di tengah-tengah masyarakat disikapi berbeda oleh para ahli di mana mereka memandang adanya sisi baik maupun buruk yang ditimbulkan oleh dalam penggunaan gadget. Smartphone memberikan kemudahan bagi masyarakat dalam berkomunikasi dengan orang lain, fungsinya bahkan berkembang menjadi alat yang betul-betul membantu pekerjaan-pekerjaan yang dilakukan oleh manusia. Dikutip dari situs Kementerian Komunikasi dan Informasi, pada tahun 2016 tercatat ada sekitar 80 juta pengguna smartphone, bahkan di tahun 2018 jumlah tersebut melonjak menjadi 100 juta. Hal ini menempatkan Indonesia menjadi negara terbesar keempat didunia setelah Cina, India, dan Amerika sebagai negara aktif pengguna smartphone. Walaupun gadget membawa sisi positif dalam membantu pekerjaan, namun para praktisi pendidikan begitu cemas dan khawatir terhadap dampak destruktif yang ditimbulkan salah satunya yaitu reduksi nilai-nilai moralitas dan spiritualitas dalam kepribadian masyarakat kontemporer pada umumnya, generasi muda pada khususnya. Hal ini diakibatkan dari derasnya konten-konten berbahaya yang begitu bebas berkeliaran dalam dunia cyber yang belum bisa difilter secara optimal, sehingga berpotensi dikonsumsi secara bebas oleh generasi muda yang pada akhirnya akan berbahaya dalam jangka panjang.

Dalam merespons dampak buruk ini, maka muncullah gagasan konsep pendidikan karakter sebagai salah satu jembatan upaya menangkal pengaruh buruk tersebut. Pakar ahli Malawi menilai 
Jurnal Penelitian Ilmu Pendidikan, 14 (2), 2021 - 129

Hyangsewu, Islamy, Parhan, \& Nugraha

bahwa implementasi pendidikan karakter di sekolah dapat diformulasikan melalui pengalaman belajar dan proses pembelajaran (Malawi, 2016). Hal ini ditegaskan oleh Ulya, mengaktualisasikan pendidikan karakter, nilai-nilai luhur yang terkandung dalam Pancasila dan Undang-Undang Dasar 1945 diharapkan dapat terinternalisasi dalam kehidupan bangsa Indonesia dan bahkan dapat menjadi way of life atau jalan hidup bangsa Indonesia (Ulya, 2017). Para praktisi pendidikan saat ini mencoba mengelaborasi serta melakukan kajian spesifik dalam mengembangkan gagasan konseptual pola pendidikan dan pengajaran yang efektif dan efisien dalam rangka meningkatkan pendidikan karakter (Badrudin, 2020; Fihris, 2018; Mudhofir, 2016; Parhan, 2018; Ramdan \& Fauziah, 2019; Rohani \& Syaifullah, 2012; Zulfa, 2018).

Studi penelitian ini mencoba menjawab rumusan penelitian bagaimanakah potret awal penggunaan gadget oleh mahasiswa dalam kehidupan sehari-hari. Selanjutnya, hal lain yaitu bagaimanakah dampak yang ditimbulkan olehnya, dan solusi praktis seperti apakah yang harus dijalankan oleh para generasi muda untuk meningkatkan sisi positif dalam penggunaan gadget.

\section{METODE}

Penelitian ini menggunakan pendekatan mix method yaitu dengan mengkombinasikan antara kualitatif yang direpresentasikan Teknik wawancara semi terstruktur terhadap pakar ahli serta pendekatan kuantitatif yang didapat dari hasil teknik pengumpulan data melalui kuesioner. Teknik pengumpulan data menggunakan random sampling terhadap 74 orang responden yang sebagian besar merupakan mahasiswa dari berbagai latar belakang jurusan pada salah satu perguruan tinggi di Bandung. Kuesioner berisi 15 instrumen pertanyaan yang dikonstruksi dari berbagai teori-teori terkait perilaku sosial. Kuesioner dalam studi ini menggunakan Google Form. Riset ilmiah ini dilakukan dalam rentang waktu 2 sampai 3 bulan yang dimulai dari bulan Februari hingga Mei 2020. Dalam rangka menyeimbangkan data temuan di lapangan, peneliti meminta pendapat salah seorang pakar ahli dalam bidang manajemen. Pakar ini berprofesi sebagai dosen di salah satu kampus di Bandung, di mana pendapatnya dijadikan sebagai salah satu pedoman dan pandangan merumuskan formulasi solusi praktis dari tantangan dan problematika yang muncul dalam diskursus penelitian ini. Tabel 1 menggambarkan distribusi responden pada 20 jurusan.

Tabel 1. Distribusi Responden menurut Jurusan

\begin{tabular}{lclc}
\hline \multicolumn{1}{c}{ Jurusan } & Jumlah & \multicolumn{1}{c}{ Jurusan } & Jumlah \\
\hline Administrasi Pendidikan & 33 & Pendidikan Ekonomi & 2 \\
Bimbingan dan Konseling & 9 & Pendidikan Sejarah & 1 \\
Teknologi Pendidikan & 7 & Pendidikan Sosiologi & 1 \\
Pendidikan Khusus & 1 & Manajemen & 2 \\
Pendidikan Kesejahteraan Keluarga & 1 & PPN & 1 \\
Pendidikan Guru SD & 2 & Pendidikan Bahasa Jepang & 1 \\
Akuntansi & 2 & Pendidikan Bahasa Inggris & 1 \\
Hukum Ekonomi & 1 & Ilmu Keolahragaan & 1 \\
Ilmu Pendidikan Agama Islam & 1 & Pendidikan Seni Rupa & 3 \\
Pendidikan Bahasa Perancis & 1 & Kimia & 3 \\
\hline Total & & & $\mathbf{7 4}$ \\
\hline
\end{tabular}

\section{HASIL DAN PEMBAHASAN}

Hasil

Dari data yang masuk, terdapat beberapa temuan yang disajikan dalam bentuk tabel agar lebih memudahkan. Selanjutnya temuan tersebut divalidasi dan dikembangkan lebih lanjut menggunakan pisau analisis teori konstruksi sosial. Tabel 2 menampilkan data temuan dari hasil kuisioner. Data temuan tersebut berdasarkan kuisioner yang dibagikan melalui Google Form kepada 74 responden dengan 12 instrumen yang harus dijawab. Data statistik pada tabel 2, hasil penelitian menunjukkan bahwa 43,80\% mahasiswa menggunakan gadget selama kurang lebih 10 jam, 32,90\% mahasiswa 
Jurnal Penelitian Ilmu Pendidikan, 14 (2), 2021 - 130

Hyangsewu, Islamy, Parhan, \& Nugraha

menggunakan gadget selama kurang lebih 7 jam, 19,20\% mahasiswa menggunakan gadget selama kurang lebih 5 jam, dan 4,10\% mahasiswa menggunakan gadget selama kurang lebih 2 jam.

Tabel 2. Data Temuan melalui Kuesioner

\begin{tabular}{|c|c|c|}
\hline No & Instrumen Pertanyaan & Temuan \\
\hline 1 & $\begin{array}{l}\text { Literasi digital gadget serta } \\
\text { fungsinya }\end{array}$ & $\begin{array}{l}98,60 \% \text { atau mayoritas mahasiswa mengetahui apa itu } \\
\text { gadget dan fungsinya }\end{array}$ \\
\hline 2 & $\begin{array}{l}\text { Intensitas dan frekuensi } \\
\text { penggunaan gadget dalam sehari }\end{array}$ & $\begin{array}{l}43,80 \% \geq \text { lebih dari } 10 \text { jam, } 32,90 \% \text { sekitar } 7 \text { jam, } \\
19,20 \% \text { sekitar } 2 \text { jam, sisanya sekitar } 1 \text { jam }\end{array}$ \\
\hline 3 & Penggunaan platform media sosial & $\begin{array}{l}\text { WhatsApp menempati rangking 1, lalu berturut-turut } \\
\text { selanjutnya Instagram, Twitter, Line, Facebook, } \\
\text { Kakaotalk }\end{array}$ \\
\hline 4 & $\begin{array}{l}\text { Bermain gadget seharian dari pada } \\
\text { interaksi sosial }\end{array}$ & $\begin{array}{l}45,90 \% \text { mayoritas lebih menyukai gadget dari pada } \\
\text { aktivitas sosial, } 47,30 \% \text { menjawab kadang-kadang, } 6,80 \% \\
\text { sepakat tidak pernah }\end{array}$ \\
\hline 5 & $\begin{array}{l}\text { Bermain gadget daripada berbicara } \\
\text { dengan teman }\end{array}$ & $\begin{array}{l}\text { b selalu, } 16,20 \% \text { menjawab kadang- } \\
\text { nayoritas tidak pernah }\end{array}$ \\
\hline 6 & $\begin{array}{l}\text { Menonton webtoon atau membaca } \\
\text { buku }\end{array}$ & $\begin{array}{l}5,40 \% \text { menjawab memilih webtoon, } 35,10 \% \text { menjawab } \\
\text { kadang-kadang, } 59,50 \% \text { tidak pernah }\end{array}$ \\
\hline 7 & $\begin{array}{l}\text { Menonton tayangan film romantis } \\
\text { atau film aksi dengan gadget }\end{array}$ & $\begin{array}{l}8,10 \% \text { selalu, } 74,30 \% \text { kadang-kadang, } 17,60 \% \text { tidak } \\
\text { pernah }\end{array}$ \\
\hline 8 & Membawa gadget kemana saja & $\begin{array}{l}83,80 \% \text { menjawab selalu, } 14,90 \% \text { kadang-kadang, } 1,30 \% \\
\text { tidak pernah }\end{array}$ \\
\hline 9 & $\begin{array}{l}\text { Menggunakan gadget saat berjalan } \\
\text { atau berkendaraan }\end{array}$ & $\begin{array}{l}7,80 \% \text { selalu, } 71,60 \% \text { kadang-kadang, } 21,60 \% \text { tidak } \\
\text { pernah }\end{array}$ \\
\hline 10 & adget & g-kadang \\
\hline 11 & $\begin{array}{l}\text { Penggunaan gadget untuk tugas- } \\
\text { tugas perkuliahan }\end{array}$ & $71,60 \%$ menjawab selalu, 28,40 kadang-kadang \\
\hline 12 & $\begin{array}{l}\text { Penggunaan gadget ketika dosen } \\
\text { mengajar di kelas }\end{array}$ & $\begin{array}{l}9,50 \% \text { menjawab selalu, } 83,80 \% \text { kadang-kadang, } 7,70 \% \\
\text { menjawab tidak pernah }\end{array}$ \\
\hline
\end{tabular}

Sedangkan Gambar 1, menampilkan media sosial yang paling sering digunakan adalah Whatsapp. setelah itu ada Instagram, Twitter, Line, Facebook, dan Kakaotalk.

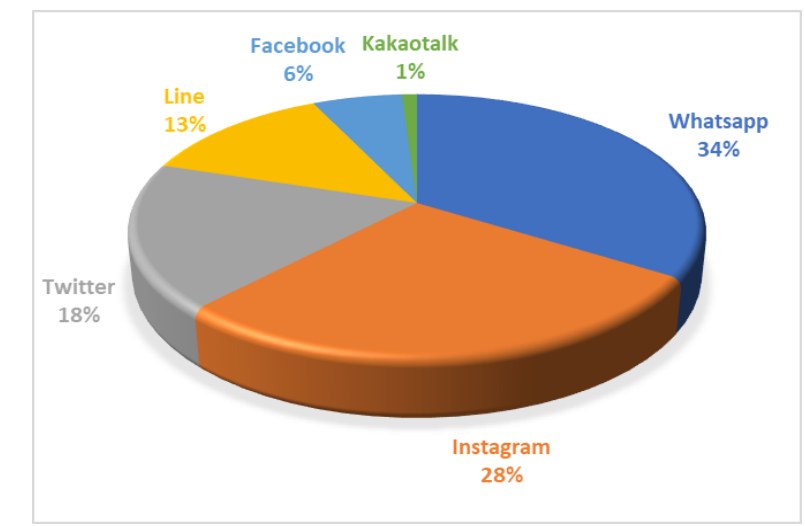

Gambar 1. Persentase pengguna aplikasi media sosial

Di samping data kuantitatif berdasarkan kuisioner, penelitian ini juga didukung dengan hasil wawancara. Pertanyaan wawancara meliputi penggunaan gadget yang baik, dengan sisi positif dan negatif yang ditimbulkan dari penggunaan gadget tersebut. Penggunaan gadget yang baik tentu saja tidak hanya diikuti dengan pengaturan waktu dalam penggunaannya namun juga dengan menyeimbangkan timbulnya pengaruh positif dan negatif. Pengaruh positif pada penggunaan gadget tersebut, dapat berupa semakin mudah dan cepatnya mendapatkan informasi. Khususnya informasi dalam bidang pendidikan, banyaknya penelitian yang mudah diperoleh, juga biaya akses yang relatif murah, hanya membutuhkan kuota internet yang memadai. Sedangkan sisi negatifnya meliputi 
Jurnal Penelitian Ilmu Pendidikan, 14 (2), 2021 - 131

Hyangsewu, Islamy, Parhan, \& Nugraha

ketergantungan pengguna pada gadget, dan seringkali menjadi pengguna lupa waktu dalam penggunaan gadget sehari-hari.

"Mahasiswa seringkali lupa waktu kalau sudah menggunakan gadgetnya, dan menjadi sangat tergantung. Mahasiswa juga terkadang jadi lebih egois, contohnya seringkali mahasiswa yang sedang menggunakan headset suka lupa dengan orang yang ada di sekitarnya" (Wawancara: 13 Maret, 2020; Jam 15.00 WIB).

Selain pengaruh positif dan negatif yang disebutkan di atas, tingginya intensitas penggunaan gadget oleh para responden juga akan memberikan pengaruh pada perilaku seseorang seperti hasil wawancara dengan pakar.

"Penggunaan gadget dapat berpengaruh terhadap perilaku seseorang ya.., di antaranya mahasiswa selalu mementingkan diri mereka sendiri karena gadget sudah jadi bagian dari hidupnya. Mahasiswa juga terkadang jadi bersifat lebih individualis dan ga mau peduli dengan sekitarnya, malah kadang membahayakan diri sendiri dan orang lain, lebih-lebih itu lho kalau sedang berkendaraan, kan bahaya itu." (Wawancara: 10 April 2020; jam 10.00 WIB).

Bahaya yang ditimbulkan dari ketergantungan pada gadget, tidak hanya pada perilaku namun juga pada fisik pengguna dan orang lain. Sehingga dibutuhkan pemecahan masalah untuk meminimalisir resiko yang mungkin timbul, seperti kecanduan gadget, bahkan kecelakaan. "Ibu berpesan, mahasiswa harus cerdas dalam menggunakan gadget agar sesuai dengan urgensitas penggunaannya." Termasuk cerdas juga dalam mengelola emosionalnya ketika mendapatkan sebuah informasi. Informasi sebelum disebarkan harus dicek dulu kebenarannya. "...Informasi sebelum disebarkan harus diperiksa terlebih dahulu kebenarannya sehingga ia menjadi terpercaya." (Wawancara: 10 April 2020; jam 10.00 WIB).

Prioritas penggunaan gadget akan berbeda-beda pada setiap individu, dan tidak dapat disamaratakan. Namun kata kunci yang dapat dijadikan pegangan adalah pengguna dapat bertanggung jawab pada saat menggunakan gadget.

“...mahasiswa perlu menerapkan Sidiq Amanah Tabligh Fathonah dalam penggunaan gadget ya... Di samping itu, para mahasiswa juga perlu didorong untuk menggunakan gadget secara tepat dan benar, berdasarkan keilmuannya. Mereka harus mampu memilih dan mengkaji mana yang baik untuk dilakukan dan mana yang tidak baik. Selain itu, Ibu berharap mahasiswa tidak menjadikan gadget sebagai satu-satunya hal yang penting di dunia. Dengan begitu, Allah tidak akan murka kepada kita, karena kita lebih mengingat gadget daripada mengingat Allah." (Wawancara: 10 April 2020; jam $10.00 \mathrm{WIB})$.

Selain hal tersebut, ada beberapa hal yang bisa dijadikan solusi untuk memecah konsentrasi pengguna pada ketergantungannya dalam menggunakan gadget. Antara lain dengan melakukan kegiatan-kegiatan sosial, keolahragaan dan seni.

“...menurut Ibu ada beberapa solusi bagi orang yang kecanduan dengan gadget ya... bisa dengan melalukan beberapa aktivitas, antara lain mengisi waktunya dengan aktivitas yang tanpa menggunakan hp. Contohnya seperti berlibur dengan keluarga, atau teman, outbound. Atau berolahraga seperti renang. Ada juga tuh dengan melakukan seni, konsentrasi mahasiswa menjadi teralihkan perhatiannya, dari menggunakan gadget sepanjang hari kepada hal-hal terkait sentuhan-sentuhan manusia atau karya seni." (Wawancara: 10 April 2020; jam 10.00 WIB).

\section{Pembahasan}

\section{Intensitas Penggunaan Gadget}

Berdasarkan data bahwa penggunaan gadget oleh sebagian besar responden adalah 10 jam per hari, maka hal ini menunjukkan bahwa mayoritas responden tidak dapat lepas dari gadget. Walaupun begitu, ada beberapa mahasiswa yang tidak selalu menggunakan gadget sehingga bisa dikatakan bahwa responden ini tidak bergantung kepada gadget. Mayoritas responden yang memiliki gadget tentunya juga selalu mengakses internet di gadget. Ada beberapa hal yang dicari responden ketika mengakses internet, diantaranya ada bahan untuk mengerjakan tugas, youtube, video inspiratif, k-pop, 
Jurnal Penelitian Ilmu Pendidikan, 14 (2), 2021 - 132

Hyangsewu, Islamy, Parhan, \& Nugraha

media sosial, berita atau informasi terkini, resep masakan, novel, drama, shopee, spotify, podcast, dan kajian muslim.

Gambar 1 juga menunjukkan bahwa skala intensitas penggunaan media sosial oleh responden lebih dari 6. Hal ini menunjukkan bahwa responden seringkali mengakses media sosial. Ada beberapa alasan mahasiswa menggunakan media sosial, di antaranya adalah untuk bersosialisasi, menyambung silaturahmi, berkenalan dengan teman baru, menjalin relasi, menghibur diri sendiri, menambah pengetahuan, mengabadikan momen, menambah penghasilan, mencari tahu tentang orang lain, bentuk aktualisasi diri, optimalisasi dakwah, dan up to date terkait berita atau informasi terkini.

Oleh karena itu, berdasarkan tingginya intensitas penggunaan media sosial tentu saja memiliki dampak yang besar bagi pengguna. Baik itu dampak langsung maupun tidak langsung yang akan berpengaruh terhadap emosional, psikis, intelektual, moral, dan juga spiritual seseorang.

Selain media sosial, ada banyak aplikasi yang digunakan oleh mahasiswa responden di gadget. Diantaranya adalah Al-quran, Muslim Pro, Kamus, e-Book, Detik.com, Olsho, Editor, Wattpad, Webtoon, Photo Editing, Cake, Tokopedia, e-Wallet, Shopee, Grab, Huji, Traveloka, Gojek, Netflix, Lightroom cc, VSCO, Picsart, Nichi, WPS, Tik Tok, Microsoft, YouTube, Spotify, Scanner, Google Translate, Duolingo, Cookpad, Tiket, m-Banking, Kalkulator, Grafik, Canva, Filmora, MINA, Google map, Musik, Ipusnas, Apple Health, Online Stocks, Game, KBBI, Khan Academy, Photomath, Pinterest, Soundcloud, April, Twitch, Nimo TV, Story Art, Share it, Pegi pegi, Im3, dan BMKG.

Seorang pakar pendidikan dunia Bobbi De Porter dalam bukunya Quantum Learning menemukan adanya peningkatan kecerdasan intelektual siswa apabila proses pembelajaran mampu melibatkan seluruh panca indera dengan konsep audio-visual (Porter \& Hernacki, 2007). Youtube dan Instagram memiliki keunggulan konsep audio-visual yang ramah dan simpel dengan dibandingkan yang lainnya, walaupun WhatsApp sudah mulai mengembangkan teknologi Audio-Visual yang lebih praktis secara bertahap sehingga mampu mengoptimalkan proses pembelajaran (Azor, Asogwa, Ogwu, \& Apeh, 2020). Ada satu konsep yang lebih efektif dan efisien dibandingkan teori AudioVisual yang ditawarkan oleh Porter dalam meningkatkan intelektualitas yaitu dengan prinsip tarbiyah Rasulullah SAW At-Thathbīq Al-'Amalī mengaktualisasikan pengetahuan (science) dengan tindakan (action). Prinsip Tarbiyyah Islamiyyah Rasulullah tersebut dikembangkan oleh seorang pakar pendidikan Muhamma Rawwas dalam karyanya Dirāsāt At-Tahlīliyyah Li Syahsyiyati Ar-Rasūl Muhammad, setidaknya ada tujuh belas prinsip efektif pola pendidikan Rasulullah SAW yang diterapkan kepada para sahabatnya sehingga melahirkan manusia-manusia religius, salah satunya prinsip di atas (Rawwas, 1988).

\section{Fungsi dan Manfaat Gadget}

Dari data statistik pada Tabel 1, mayoritas mahasiswa menunjukkan mengetahui apa itu gadget dan fungsinya. Hasil menunjukkan bahwa 98,60\% mahasiswa mengetahui tentang gadget dan kegunaannya, walaupun demikian masih ada mahasiswa yang tidak mengetahui apa itu gadget dan kegunaannya. Dari jawaban-jawaban yang ditemukan, beberapa alasan mahasiswa menggunakan gadget diantaranya yaitu; 1) Gadget merupakan kebutuhan primer, lifestyle, dan juga memudahkan kebutuhan manusia. Selain itu gadget juga modern atau terkini dan fleksibel untuk digunakan, 2) Gadget digunakan untuk berkomunikasi, bersilaturahmi, berkoordinasi dengan teman, keluarga yang jauh, rekan kerja, dan orang baru dalam rangka memperluas relasi, 3) Gadget digunakan untuk menggali informasi melalui aplikasi pencari, berbagi informasi melalui berita terkini, dan berdakwah, 4) Gadget digunakan untuk belajar melalui media pembelajaran, mengerjakan tugas, membuka dokumen, dan menghasilkan karya, 5) Gadget digunakan untuk menghibur seperti melihat foto, video, film, belanja online, dan juga bermain games, 6) Gadget digunakan untuk menambah penghasilan dengan e-commerce. Dalam sebuah studi yang dilakukan oleh Rahmawati (2020), gadget setidaknya memiliki posisi strategis dalam membangun perkembangan pendidikan anak dengan cara mengoptimalkan fungsinya sebagai sarana komunikasi, sarana sosial, sarana media belajar, dan sarana membangun karakter (Rahmawati, 2020).

Sebuah teori yang dikembangkan oleh Harold Lasswell mengatakan bahwa cara yang paling baik dalam menerangkan proses komunikasi dengan cara membangun pertanyaan $5 \mathrm{~W}$ (What, Who, Why, Where, When) (Syahudin, 2019). Teori Harold di atas berdampak terhadap pola yang seperti 
Jurnal Penelitian Ilmu Pendidikan, 14 (2), 2021 - 133

Hyangsewu, Islamy, Parhan, \& Nugraha

apakah yang harus dibangun terhadap para mahasiswa dalam meminimalisir dampak buruk terhadap perilaku social behaviour mereka. Selanjutnya, dalam pandangan agama Islam, aspek mashlahat merupakan standarisasi dalam terwujudnya hukum-hukum fiqih. Dalam karyanya berjudul Ushūl $\mathrm{Al}$ 'Amal Al-Khairī F̄̄ Al-Islām F̄̄ Dhaui An-Nushūsh Wa Al-Maqāsid As-Syarī'a syeikh Yusuf AlQardhawi menegaskan bahwa perbuatan baik setidaknya harus dibangun dari 5 karakteristik utama; pertama, As-Syumul universalitas, kedua, At-Tanawwu' kategorisasi, ketiga Al-Istimrar konsistensi, keempat, Ikhlas Lillahi Ta'ala, kelima, Al-Khulush Lil Khair (Al-Qardhawi, 2007). Gadget dapat diposisikan sebagai alat yang memiliki dua sisi yang berbeda yaitu baik maupun buruk, tergantung pemanfaatannya oleh pengguna. Oleh sebab itu, dalam prinsip-prinsip syari'ah agama Islam, memperhatikan aspek maqashid syari'ah sangat dibutuhkan, di mana esensi darinya yaitu setiap syari'ah yang ditetapkan oleh nash berorientasi pada mewujudkan kebaikan pada manusia, dan menjauhkan dari hal-hal yang merusak (Al-Qardhawi, 2000).

\section{Dinamika Dampak Penggunaan Gadget terhadap Perilaku Sosial}

Ada banyak Selanjutnya, berdasarkan data yang diperoleh dari pendapat responden, mayoritas mengatakan bahwasanya gadget memiliki pengaruh terhadap perilaku seseorang. Adapun pengaruh tersebut ada yang pengaruh baik dan pengaruh buruk. Di antara pengaruh baiknya antara lain orang menjadi termotivasi, up to date dengan segala informasi, rajin belajar, menjadi lebih kritis, menjadi lebih baik, menghargai orang lain, dan wawasan lebih luas dari yang sebelumnya. Contoh dari pengaruh buruk antara lain berpengaruh terhadap psikologis seseorang, orang memiliki 2 dunia, merubah pola pergaulan, waktu terbuang sia-sia, menunda-nunda pekerjaan, malas belajar, selalu iri dengan pencapaian orang lain, tidak bersyukur atas apa yang dimiliki, individualisme, kecanduan gadget, lupa beribadah, kurang percaya diri, malas beraktivitas, antisosial, apatisme, memperburuk kesehatan, mencari informasi orang lain, dan terkena penipuan.

Dalam satu penelitian, Iswanti menyimpulkan bahwa gadget sangat berpengaruh terhadap perilaku sosial seseorang. Perilaku sosial yang positif di antaranya adalah bagaimana alat ini dapat membantu para remaja membangun satu komunikasi efektif dengan teman sebayanya maupun orangorang terdekat dengannya. Selain itu, sisi baik lainnya adalah dengannya dapat memudahkan seseorang untuk dapat mengekspresikan berbagai macam perasaan dalam sebuah kondisi psikologis tertentu (Iswanti, 2020). Hal ini tentunya agak selaras dengan data temuan di lapangan, di mana dari hasil pernyataan mahasiswa responden di atas diketahui bahwasannya mayoritas mahasiswa responden bergantung kepada gadget dalam kehidupan sehari-harinya. Hal ini dikarenakan gadget mendatangkan manfaat bagi mahasiswa. Manfaat yang diperoleh mahasiswa melalui gadget di antaranya adalah membantu dalam mengerjakan tugas, menjalankan bisnis, dan juga terhibur karena membaca buku/ webtoon, bermain game, dan juga menonton film genre romantis/aksi dengan gadget. Mayoritas mahasiswa pun masih beretika ketika menggunakan media sosial, terbukti salah satu perilaku yang tidak mencemooh atau berkomentar miring terhadap orang lain di media sosial. Begitu pula ketika menggunakan gadget untuk melihat video, mayoritas mahasiswa tidak mengakses kontenkonten yang destruktif (Parhan, Lukman, Hikhmalia, \& Rosid, 2020).

Dampak buruk penggunaan gadget disoroti oleh Rahmandani dan timnya dalam sebuah studi riset yang dilakukan pada sejumlah siswa SMA, di antara perubahan karakter yang dialami siswa yaitu lebih pasif, lebih individualis, lebih apatis (Rahmandani, Tinus, \& Ibrahim, 2018). Temuan ini semakin memperkuat hasil penelitian terkait dampak buruk yang ditimbulkan. Selain itu, gadget juga memberikan pengaruh buruk terhadap perilaku mahasiswa. Perilaku buruk tersebut di antaranya adalah mahasiswa yang kecanduan terhadap gadget terbukti dengan mahasiswa yang membawa gadget kemanapun ia pergi walaupun sedang berjalan atau berkendara yang tentunya hal ini berbahaya tidak hanya bagi mahasiswa itu sendiri melainkan juga terhadap orang lain yang bisa terpengaruh dari perilaku mahasiswa tersebut. Selain itu, dengan gadget juga mahasiswa terkadang menjahili temannya dan bahkan juga seringkali lupa waktu kapan gadget harus digunakan sehingga pembelajaran di kelas pun mahasiswa masih menggunakan gadget. Di samping gadget ada beberapa dampak buruk yang ditimbulkan oleh sosial media dan dirasakan langsung oleh mahasiswa, mereka lebih mencari hiburan dibanding informasi, bebas akses dan berakibat rasa ingin tahu lebih, kemudian menyita waktu, membuat lalai, lupa waktu, dan kecanduan, kurangnya manajemen waktu, dan kuota banyak terbuang. Selain itu berkurangnya bertemu dan bersosial secara langsung (offline), penyebaran 
Jurnal Penelitian Ilmu Pendidikan, 14 (2), 2021 - 134

Hyangsewu, Islamy, Parhan, \& Nugraha

berita bohong lebih mudah, literasi fisik berkurang, rasa minder, media yang kurang bijak dan santun dalam menggunakan sosial media, selanjutnya bisa menimbulkan addictive, terkadang kepala menjadi pusing, mengganggu istirahat karena keasyikan bermain sosial media, tidak baik bagi kesehatan mata, dan begadang karena main game.

Namun demikian, di sisi lain, menurut Febey \& Qalbi dalam studi ilmiahnya menemukan bahwa gadget dapat berdampak positif pada siswa diantaranya sebagai upaya dalam pengembangan dan peningkatan kognitif pada siswa (Febey \& Qalbi, 2020). Sisi baik yang disoroti oleh Febey \& Qalbi memperlihatkan bahwa sejatinya gadget hanyalah sebuah alat, di mana sisi baik dan sisi buruk akan tetap ada. Gadget jika dikaitkan dengan ibadah seperti halnya sebuah pisau yang mana bisa berguna maupun membahayakan. Adapun penggunaan gadget dengan bijaksana dapat menghasilkan suatu manfaat besar dalam beribadah seperti halnya aplikasi muslim di gadget contohnya Alquran digital yang mudah dibawa kemanapun, muslim pro yang selalu untuk mengingatkan untuk berbuat kebaikan, Google dan media sosial sebagai sarana dakwah dan juga menambah pengetahuan. Namun jika digunakan dengan tidak bijaksana, gadget bisa membuat orang sehingga ia lalai dalam beribadah, menunda-nunda pekerjaannya, dan bahkan menjerumuskannya ke dalam pergaulan yang tidak baik.

Analisa yang peneliti lakukan memiliki beberapa catatan dan kelemahan, yang mudahmudahan riset ini dapat disempurnakan oleh penelitian-penelitian di masa yang akan datang sehingga dapat berkontribusi besar dalam merespon kekhawatiran adanya dampak destruktif dari ini. Hasil penelitian ini bisa dijadikan satu potret informasi awal, sehingga informasi ini dapat berkontribusi dalam rangka menemukan kebijakan seperti apakah yang harus diambil baik oleh pemerintah maupun para praktisi pendidikan dalam rangka menanggulangi dampak buruk tersebut, dan akhirnya generasi muda khususnya para mahasiswa dapat diarahkan kepada hal-hal positif yang dapat meningkatkan kompetensi literasi digital, critical thinking, dan pengembangan kesalehan individu mereka. Hal ini tentunya selaras dengan nilai-nilai ajaran Islam, di mana Islam menekankan pentingnya aspek moralitas akhlak sebagai komponen fundamental (Al-Qardhawi, 1990). Selaras dengan Al-Qardhawi, Syeikh Abdurrahman Al-Arefe dalam karyanya "Istamti' bi Hayatik" menjelaskan bahwa dakwah yang dilakukan oleh Rasulullah SAW betul-betul memainkan peran akhlak dalam meraih simpati masyarakat Arab Jahiliyyah pada saat itu sehingga Islam menjadi agama yang rahmatan lil alamin (Al-Arefe, 2011).

\section{PENUTUP}

Globalisasi memberikan dampak yang begitu besar dalam dinamika kehidupan masyarakat modern umumnya serta mahasiswa pada khususnya. Salah satunya yaitu efek yang ditimbulkan begitu dirasakan terhadap pola sikap dan perilaku sosial mahasiswa di Perguruan Tinggi. Dari hasil penelitian yang dilakukan terlihat bahwa adanya relevansi koneksitas antara penggunaan gadget dengan perubahan dinamika perilaku sosial pada mahasiswa di perguruan tinggi. Globalisasi menjadi salah satu faktor bergeser dan bertransformasinya pola aktivitas dan pola pemikiran pada masyarakat modern pada umumnya dan generasi millennial pada khususnya. Perhatian serius harus betul-betul menjadi perhatian Bersama yaitu dampak gadget terhadap perilaku buruk mahasiswa berupa kecanduan terhadap gadget.

\section{DAFTAR PUSTAKA}

Al-Arefe, M. bin A. (2011). Istamti' bi hayātika funūn at-ta'āmul ma'a an-nās fì dzilli as-sìrah annabawiyyah. Saudi Arabia: Sarikah Muslim.

Al-Laham, A. I. (1956). Al-qawā'id wa al-fawāid al-ushūliyyah wa mā yata'allaq bihā min al-ahkām al-far'iyyah (p. 347). As-Sunnah Al-Muhammadiyyah.

Al-Qardhawi, Y. (1990). Awlawiyyat al-harakah al-Islamiyyah. Cairo: Dar An-Nasyr wa At-Tauji'.

Al-Qardhawi, Y. (2000). Nadzriyyah maqāsid as-syarī'ah baina syaikh al-Islām Ibnu Taimiyyah wa jumhūr al-ushüliyyīn dirāsah muqāranah min al-qarni al-khāmis ilā al-qarni ats-tsāmin alhijrī. Cairo: Dar Al-Uloom College. 
Jurnal Penelitian Ilmu Pendidikan, 14 (2), 2021 - 135

Hyangsewu, Islamy, Parhan, \& Nugraha

Al-Qardhawi, Y. (2007). Ushūl al-'Amal al-khairī fì al-Islām fì dhaui an-nushūsh wa al-maqāsid assyarīah. Cairo: Dar As-Syuruq.

Al-Rawashdeh, M. S. (2014). The impact of globalization on the political culture of the Arab youths. Journal of Middle Eastern and Islamic Studies (in Asia), 8(4), 81-120. https://doi.org/10.1080/19370679.2014.12023250.

Al-Thivierge, G.-R. (2003). Globalization and Catholic higher education: A dialogue for harnessing the impact of globalization. Higher Education in Europe, 28(1), 79-82. https://doi.org/10.1080/0379772032000110152.

Albrow, M., Eade, J., Washbourne, N., \& Durrschmidt, J. (1994). The impact of globalization on sociological concepts: Community, culture and milieu. Innovation: The European Journal of Social Science Research, 7(4), 371-389. https://doi.org/10.1080/13511610.1994.9968418.

Azor, R. O., Asogwa, U. D., Ogwu, E. N., \& Apeh, A. A. (2020). YouTube audio-visual documentaries: Effect on Nigeria students' achievement and interest in history curriculum. Journal of Educational Research, 113(5), 317-326. https://doi.org/10.1080/00220671.2020.1819182.

Badrudin, B. (2020). The management of strengthening the mosque-based religious character education. Nadwa, 13(2), 179. https://doi.org/10.21580/nw.2019.13.2.4106.

Bruner, R. F., \& Iannarelli, J. (2011). Globalization of management education. Journal of Teaching in International Business, 22(4), 232-242. https://doi.org/10.1080/08975930.2011.653908.

Febey, H., \& Qalbi, Z. (2020). Dampak permainan gadget dalam mempengaruhi perkembangan kognitif. Pena Paud, 1(1), 27-39.

Fihris, F. (2018). Model pendidikan karakter melalui homestay di SDIT cahaya bangsa Semarang. Edukasia Islamika, 3(2), 131. https://doi.org/10.28918/jei.v3i2.1684.

Goodwin, A. L. (2020). Globalization, global mindsets and teacher education. Action in Teacher Education, 42(1), 6-18. https://doi.org/10.1080/01626620.2019.1700848.

Iswanti, D. I. (2020). Penggunaan gadget terhadap perilaku sosial remaja. Jurnal Keperawatan Volume, 12(4), 815-822.

Law, W. W., \& Ho, W. C. (2009). Globalization, values education, and school music education in China. Journal of Curriculum Studies, 41(4), 501-520. https://doi.org/10.1080/00220270802372329.

London, J. D. (2010). Globalization and the governance of education in Viet Nam. Asia Pacific Journal of Education, 30(4), 361-379. https://doi.org/10.1080/02188791.2010.520202.

Machingambi, S. (2014). The impact of globalisation on higher education: A marxist critique. Journal of Sociology and Social Anthropology, 5(2), 207-215. https://doi.org/10.1080/09766634.2014.11885625.

Mah, J. S. (2002). The impact of globalization on income distribution: the Korean experience. Applied Economics Letters, 9(15), 1007-1009. https://doi.org/10.1080/13504850210149124.

Malawi, I. (2016). Implementasi pendidikan karakter melalui pembelajaran dalam mata pelajaran di sekolah dasar. Premiere Educandum: Jurnal Pendidikan Dasar Dan Pembelajaran, 3(01), 112. https://doi.org/10.25273/pe.v3i01.55.

Mudlofir, A. (2016). Pendidikan karakter: Konsep dan aktualisasinya dalam sistem pendidikan Islam. Nadwa, 7(2), 229. https://doi.org/10.21580/nw.2013.7.2.560.

Nieto, S. (2013). Diversity, globalization, and education: What do they mean for teachers and teacher educators? Kappa Delta Pi Record, 49(3), 105-107. https://doi.org/10.1080/00228958.2013.819183.

Parhan, M. (2018). Kontekstualisasi materi dalam pembelajaran. ADI WIDYA: Jurnal Pendidikan Dasar, 3(1), 7-18. http://ejournal.ihdn.ac.id/index.php/AW.

Parhan, M., Lukman, D. I. N., Hikhmalia, A. A., \& Rosid, A. A. A. A. (2020). Aktualisasi iman dan taqwa terhadap penggunaan smartphone di kalangan mahasiswa. HIKMAH: Jurnal Ilmu Dakwah dan Komunikasi Islam, 14(2), 255-270. https://doi.org/https://doi.org/10.24952/hik.v14i2.3210.

Porter, B. De, \& Hernacki, M. (2007). Quantum learning: Membiasakan belajar nyaman dan menyenangkan. Bandung: Kaifa. 
Jurnal Penelitian Ilmu Pendidikan, 14 (2), 2021 - 136

Hyangsewu, Islamy, Parhan, \& Nugraha

Rahmandani, F., Tinus, A., \& Ibrahim, M. M. (2018). Analisis dampak penggunaan gadget (smartphone) terhadap kepribadian dan karakter (kekar) peserta didik di SMA Negeri 9 malang. Jurnal Civic Hukum, 3(1), 18-44. https://doi.org/10.22219/jch.v3i1.7726.

Rahmawati, Z. D. (2020). Penggunaan media gadget dalam aktivitas belajar dan pengaruhnya terhadap perilaku anak. TA"LIM: Jurnal Studi Pendidikan Islam, 3(1), 97-113.

Ramdan, A. Y., \& Fauziah, P. Y. (2019). Peran orang tua dan guru dalam mengembangkan nilai-nilai karakter anak usia sekolah dasar. Premiere Educandum: Jurnal Pendidikan Dasar Dan Pembelajaran, 9(2), 100. https://doi.org/10.25273/pe.v9i2.4501.

Rawwas, M. (1988). Dirasah tahliliyyah li syahshiyati ar-rasul Muhammad (pp. 1-303). Dar AnNafais.

Rohani, S., \& Syaifullah, H. (2012). Optimalisasi pendidikan kembangkan kemandirian anak berkebutuhan khusus (Ab ). Jurnal Nadwa, 6(1), 179-194.

Syahudin, D. (2019). Pengaruh gadget terhadap pola interaksi sosial dan komunikasi siswa. GUNAHUMAS Jurnal Kehumasan, 2(1), 273-282.

Tight, M. (2021). Globalization and internationalization as frameworks for higher education research. $\begin{array}{llll}\text { Research Papers in } & \text { 56-74), }\end{array}$ https://doi.org/10.1080/02671522.2019.1633560.

Ulya, I. (2017). Internalisasi karakter sensitif gender dalam kurikulum pendidikan. Edukasia Islamika, 2(1), 107. https://doi.org/10.28918/jei.v2i1.1664.

Utsumi, T. (2006). Global university system for engineering education in the age of globalization. European Journal of Engineering Education, 31(3), 339-348. https://doi.org/10.1080/03043790600644081.

Weldon, P. A., Rexhepi, J., Chang, C. W., Jones, L., Layton, L. A., Liu, A., Mckibben, S., Misiaszek, G., Olmos, L., Quon, A., \& Torres, C. A. (2011). Globalization and higher education in Southern California: Views from the professoriate. Compare, 41(1), 5-24. https://doi.org/10.1080/03057925.2010.532360.

Zulfa, U. (2018). Model of Islamic religion education 435 based on Islam nusantara on college. Nadwa Jurnal Pendidikan Islam, 12(1), 1-12. 